\title{
Regional variations in potential groundwater recharge from spring barley crop fields in the UK under projected climate change
}

\author{
Yawson $^{\mathrm{a}, \mathrm{b}} *$ DO, Aduc MO, Mulholland ${ }^{\mathrm{d}}$ B, Balle T, , Frimpong ${ }^{\mathrm{f}}$ KA, Mohan $\mathrm{S}$, White ${ }^{\mathrm{h}}$ PJ \\ ${ }^{a}$ Centre for Resource Management and Environmental Studies (CERMES), The University \\ of the West Indies, Cave Hill Campus, Bridgetown, Barbados. \\ ${ }^{b}$ Department of Environmental Science, University of Cape Coast, Cape Coast, Ghana \\ c Department of Crop Science, University of Cape Coast, Cape Coast, Ghana. Email: \\ michael.adu@ucc.edu.gh
}

d ADAS UK Ltd., Battlegate Road, Boxworth, Cambridge CB23 4NN, UK. Email: barry.mulholland@adas.co.uk

e Humanities and Social Sciences, University of Winchester, Sparkford Road, Winchester SO22 4NR, UK. Email: tom.ball@winchester.ac.uk

${ }^{f}$ Department of Soil Science, University of Cape Coast, Cape Coast, Ghana

g Brighton Business School, University of Brighton, Moulsecoomb, Brighton, BN2 4AT, UK.

Email: s.mohan@brighton.ac.uk

h Ecological Sciences, The James Hutton Institute, Invergowrie, Dundee, DD2 5DA, UK.

Email: philip.white@hutton.ac.uk

*Corresponding author: david.yawson@cavehill.uwi.edu

\begin{abstract}
This study assessed the variations in the impacts of climate change on potential groundwater recharge from barley crop fields in fourteen UK administrative regions. Future climate data, based on the high, medium and low emissions scenarios (or HES, MES, and LES, respectively), were obtained from the UK Climate Projections 2009 (UKCP09) using the weather generator embedded therein. These were used, together with soil, field and calibrated data of the barley genotype Westminster, to simulate potential groundwater recharge in barley crop fields for the 2030s, 2040s, and 2050s. The results show significant variations in potential groundwater recharge for the regions and the emissions scenarios but not the time slices. There was no interaction effect between time and emissions scenarios. For all emissions scenarios, time slices and regions, the largest reduction and increase in potential groundwater recharge over baseline values were $38 \%$ and $41 \%$, respectively. East Midlands had the largest reductions for all time slices and emissions scenarios while Southwest Scotland, Northwest Scotland, Northern Ireland and Wales had the largest increase in potential recharge over baseline values. Generally, reductions were prevalent in the south and the eastern regions of England. Reductions were also highest under HES and lowest under the LES. In the 2030s, the largest reductions were $37 \mathrm{~mm}$ (HES), $29 \mathrm{~mm}$ (MES), and $16 \mathrm{~mm}$ (LES). In the 2050s, the largest reductions were $31 \mathrm{~mm}$ (HES), $27 \mathrm{~mm}$ (MES), and $19 \mathrm{~mm}$ (LES). It is concluded that the regional variations in potential recharge in arable crop fields during the spring-summer season can be a useful input in adaptation planning that integrates
\end{abstract}


agriculture and water resources management in response to flood and drought risks, and water-food security needs.

Key words: drainage, groundwater, potential recharge, climate change, spring barley, UK climate projections

\section{Introduction}

Groundwater constitutes about $30 \%$ of the global freshwater resources and about $96 \%$ of liquid water (excluding icecaps and glaciers) (Green et al., 2011; UNESCO, 2008). Groundwater contributes significantly to the world's domestic, industrial and agricultural water supplies (Siebert et al., 2010; Giordano, 2009; Holman et al., 2009). For example, globally, groundwater accounts for about $43 \%$ of the $1277 \mathrm{~km}^{3} \mathrm{yr}^{-1}$ total consumptive irrigation water use, and about $38 \%$ of the 301 million ha of land equipped for irrigation (Siebert et al., 2010). Being an important component of the hydrological cycle, groundwater is recharged naturally or directly through infiltration (entry of water from the soil surface into the subsurface) and subsequent drainage or percolation (further downward movement of infiltrated water from the root zone). Potential groundwater recharge can be considered as the volume or depth of water that drains or percolates from the unsaturated root zone to an underlying aquifer or saturated zone under a given combination of climate and land use/land cover (Scanlon et al., 2006). Such recharge depends, principally, on hydrometeorological factors (e.g. quantity, intensity and duration of precipitation), hydrogeological conditions of the surface (e.g. geomorphology, geology and pedology), and the land use or cover of the area of interest (Siebert et al., 2010). For the purpose of the current study, potential recharge refers to the depth of water that drains from the unsaturated root zone and can potentially reach the underlying saturated zone.

Food production and water availability are intricately linked (Yawson et al., 2013; Thenkabail et al., 2010). However, this relationship is often conceived in terms of consumptive use of water for food production, rather than the potential of agriculture to contribute to water availability. In terms of spatial extent, agriculture is the largest human activity on land (Thenkabail et al., 2010). Through its spatial extent and direct effects on infiltration and percolation, agriculture plays a key role in potential groundwater recharge. Thus, rain-fed crop production contributes to natural, diffuse recharge of groundwater as it plays a role in the quantity, quality and rate of infiltration and percolation through the unsaturated zone to the underlying acquifer. An understanding of this contribution of crop fields to potential groundwater recharge is important for sustainable management of water resources and associated risks. In the context of climate change, estimates and understanding 
of future contributions of crop fields to potential groundwater recharge would be useful for adaptive responses to climate change impacts on groundwater resources and agronomic management practices such as drainage of crop fields.

Precipitation is the major input to groundwater recharge but this is mediated by the nature of the surface and soil hydraulic properties. Climate change projections suggest, generally, warmer temperatures and increased variability in precipitation (IPCC, 2007). Spatial and temporal shifts, as well as changes in the magnitude of precipitation, will directly affect crop water use, water storage in the root zone and drainage losses from the unsaturated root zone to underlying aquifers. Generally, the impacts of climate change on surface water have been widely studied compared to groundwater recharge, resulting in poor understanding of the impacts of climate change on groundwater recharge globally (Green et al., 2011; Jackson et al., 2011; Holman et al., 2009; Mileham et al., 2008; IPCC, 2007) and in the UK (Jackson et al., 2011). This is due principally to poor availability of data, the complicated and highly variable spatial-temporal responses of groundwater to climate change, and difficulties associated with quantifying groundwater storage (Green et al., 2011; IPCC, 2007). Because it is difficult to accurately quantify the effects of climate change on groundwater storage, studies have largely focused on recharge rates at the catchment scale, with some indicating potentially reduced recharge rates (e.g. Herrera-Pantoja and Hiscock, 2008; Kruger et al., 2001), while others indicate potential increases in recharge rates (e.g. Jyrkama and Sykes, 2007; Kovalevskii, 2007). While the uncertainties of the impacts of climate change on groundwater might be large and pervasive, crop cultivation would certainly affect both direct and diffuse potential recharge of groundwater. Yet, there is little information about future contributions of arable crop fields to potential groundwater recharge across different spatialtemporal scales (Mileham et al., 2008; Green et al., 2011). Further, these contributions are largely neglected in the overall assessments of the effects of climate change on future water resources. The advances in crop-growth simulation models can permit simulation-based assessment of contribution of crop fields to potential groundwater recharge under projected climate change. This, in turn, will permit integration of potential groundwater recharge from crop fields into the assessments of water resources and related management decisions under future climates.

Climate change will likely have varied effects on the contribution to potential groundwater recharge from arable crop fields depending on spatial variability in hydraulic properties and even the distance of the underlying aquifer from the recharge areas (Green et al., 2011). In the UK, there is a heavy reliance on groundwater for domestic, agricultural and industrial uses, especially in England and Wales (Jackson et al., 2011; Hiscock, 2005) and agriculture has the largest share of land use (Defra, 2017). As a result, potential recharge from arable crop fields in the future would be an important factor in the adaptive groundwater and agronomic management responses to climate change in the UK. To this end, the current study aims at contributing to the understanding of potential recharge from crop fields under projected climate change to support such adaptive decisions in the future. The study therefore 
assessed the variations in potential groundwater recharge from spring barley crop fields in the fourteen UK administrative regions (see Figure 1) under projected climate change.

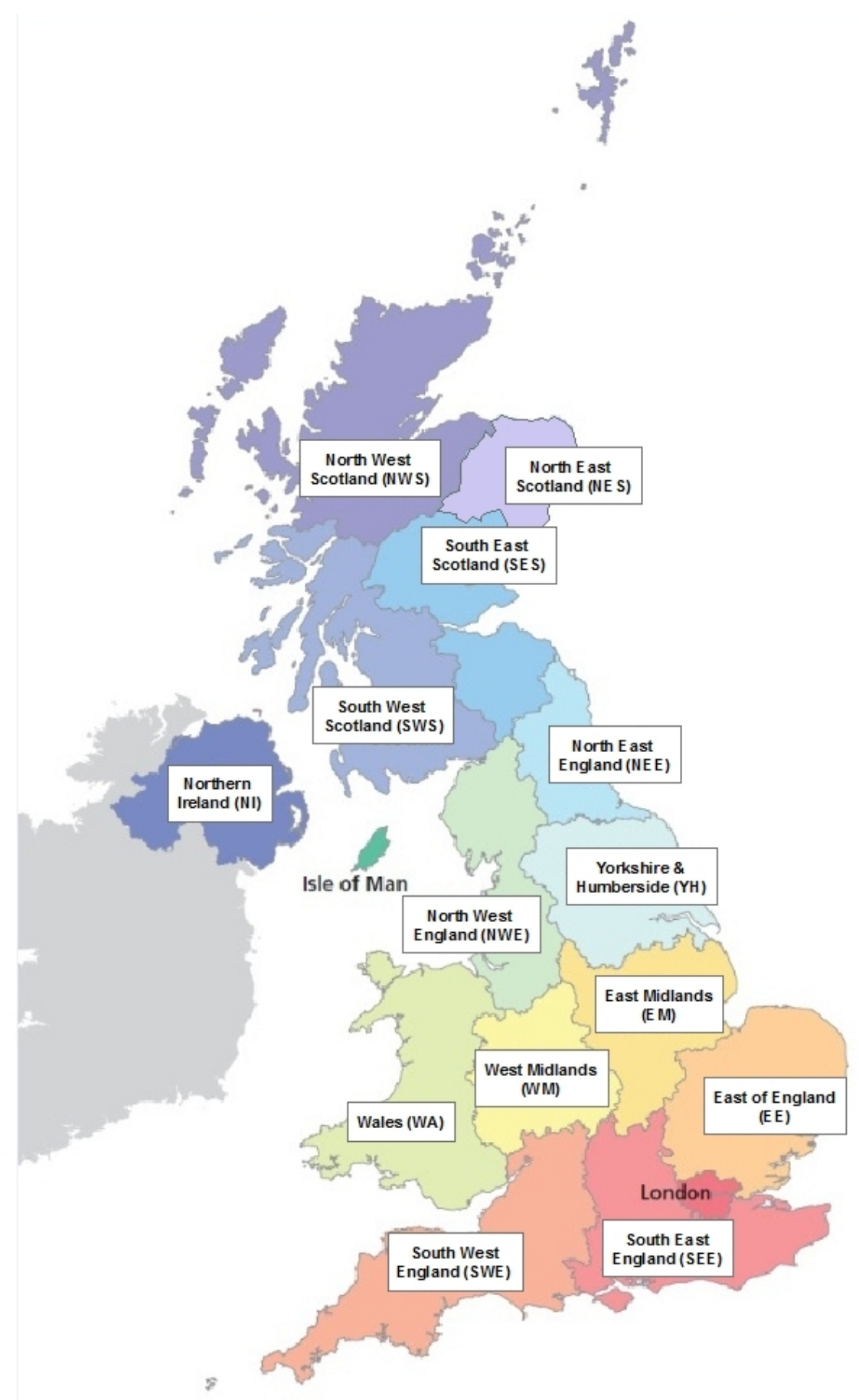

Figure 1: A map of the fourteen UK administrative regions.

\section{Methods}




\section{Data Sources}

Soil Data

Data on soil types, depth and hydraulic properties for the UK were obtained from the New Soil Information System (SINFO) database, which is part of the European Union programme on Monitoring Agriculture with Remote Sensing (MARS) Crop Yield Forecasting System (MCYFS). The scale of the soil data in the SINFO database is 1:1,000,000. Detailed description of this database and crop monitoring system can be found in Baruth et al. (2006). Even though there was a 1:250,000 soil data (HOST data) for the UK (which provides a greater spatial detail), it was not freely accessible. In the SINFO database, Europe is divided into Soil Mapping Units (SMU), each comprising a number of Soil Typological Units (STUs) with attributes describing the properties of the soils. In this system, soil texture and bulk density were the main determinants of soil water retention properties which, together with rooting depth, determine the hydraulic properties of the soil groups. The available water capacity (AWC) is defined for each soil group and the product of AWC and rooting depth provides the maximum available water a given soil can supply to a plant. Using ArcGIS version 9.1 (ESRI ${ }^{\mathrm{TM}}$, USA), the area covering the UK was clipped and related attribute tables were joined into a single attribute table with all the relevant attributes for the soil polygons representing the UK. Out of the eight main soil texture classes in the database, the UK had five, with the dominant texture class being 'medium'. This national map was intersected with the UK regions to obtain regional distribution of soils and related properties. As soil bulk density and texture were the main determinants of soil water retention properties in the database, the selection of dominant soil class for each region was also based on texture. For each region, the soil class with the largest spatial distribution was selected as the dominant and representative soil class for that region. The weighted averages of the values of the hydraulic properties of the selected soil polygons representing the dominant soil class were used to represent the respective regions. However, where peat was dominant, the next dominant soil class was used. The hydraulic properties obtained from the SINFO database are shown in Table 1.

Table 1: Soil hydraulic properties obtained from the SINFO database and used in the simulations. Data taken from the SINFO database (Baruth et al., 2006).

\begin{tabular}{|c|c|c|c|c|c|c|}
\hline $\begin{array}{c}\text { Admin. } \\
\text { Sub-region }\end{array}$ & $\begin{array}{c}\text { Dominant } \\
\text { Soil }\end{array}$ & $\theta_{\text {sat }}$ & $\theta_{\text {pwp }}$ & $\theta_{\text {fc }}$ & $\begin{array}{c}\text { Rooting Depth } \\
(\mathrm{m})\end{array}$ & $\begin{array}{c}\theta_{\text {asw }} \\
(\mathrm{mm} / \mathrm{m})\end{array}$ \\
\hline EE & Medium & 0.42 & 0.18 & 0.33 & 7 & 150 \\
\hline EM & Fine & 0.49 & 0.29 & 0.43 & 6.8 & 140 \\
\hline NI & Medium & 0.41 & 0.16 & 0.31 & 6.6 & 150 \\
\hline NEE & Medium & 0.42 & 0.18 & 0.34 & 6.6 & 160 \\
\hline NES & Medium & 0.41 & 0.15 & 0.30 & 6.1 & 150 \\
\hline NWE & Medium & 0.43 & 0.19 & 0.34 & 6.4 & 150 \\
\hline NWS & Medium & 0.40 & 0.15 & 0.29 & 7.0 & 140 \\
\hline SEE & Medium fine & 0.55 & 0.14 & 0.49 & 5.9 & 350 \\
\hline SES & Medium & 0.41 & 0.15 & 0.32 & 6.2 & 170 \\
\hline SWE & Medium fine & 0.58 & 0.15 & 0.50 & 4.4 & 350 \\
\hline
\end{tabular}




\begin{tabular}{|c|l|l|l|l|l|l|}
\hline SWS & Medium & 0.41 & 0.15 & 0.31 & 6.4 & 160 \\
\hline WA & Medium & 0.45 & 0.22 & 0.37 & 6.9 & 150 \\
\hline WM & Medium & 0.45 & 0.22 & 0.37 & 6.7 & 150 \\
\hline YH & Medium & 0.43 & 0.19 & 0.35 & 6.5 & 160 \\
\hline
\end{tabular}

Note: $\theta$ sat is saturated water content; $\theta$ pwp is water content at permanent wilting point; $\theta \mathrm{fc}$ is water content at field capacity; $\theta$ asw is total available soil water.

\section{Climate Data}

Projected daily climate data were generated for three time slices, 30-year periods centred on the 2030s, 2040s and 2050s, for the fourteen (14) UK administrative regions using the weather generator (WG) embedded in the UK Climate Projections 2009 (UKCP09). The UKCP09 is probabilistic and the data are averaged over monthly, seasonal and annual scales (Murphy et al., 2009). However, the WG allows a stochastic generation of statistically credible future climate variables at $5 \mathrm{~km}$ resolution on daily or hourly scales from the probabilistic projections (Jones et al., 2009). The future daily datasets were generated under the low, medium and high emissions scenarios (representing the B1, A1B and A1FI, respectively) in the UKCP09. The UKCP09 has been described in detail by Murphy et al. (2009) and the Weather Generator embedded therein has been explained by Jones et al. (2009). For each run of the WG, 100 random data samples were generated from 10,000 variants randomly sampled from the probabilistic projections. The climate data required for the simulations were then extracted from the 100 climate files that resulted from WG request for each region, time slice and emissions scenario. A detailed explanation of the generation and processing of the future climate data can be found in Yawson (2013).

The atmospheric carbon dioxide concentration for the low and medium emissions scenarios and for the three time slices of interest were available in AquaCrop. However, the projected atmospheric carbon dioxide concentration for the high emissions scenario was obtained from the IPCC data distribution centre.

\section{Simulations}

The AquaCrop model was used to simulate the yield of spring barley crop and water losses beyond the root zone under projected climate change. The simulations were based on the barley genotype Westminster. The AquaCrop model was calibrated for the genotype Westminster using field data obtained under Scottish conditions (see Yawson, 2013), together with information from Raes et al. (2009). According to the Home Grown Cereals Association (HGCA) Recommended List, the genotype Westminster is widely grown in the UK, both as spring and winter barley and is high yielding. The crop parameters used in AquaCrop can be found in Appendix 1.

AquaCrop is a crop-water productivity model from the Food and Agriculture Organization. It has been shown to be effective in simulating crop responses to soil water dynamics and climatic conditions. Details of the structure and algorithms of the subcomponents have been 
reported by Steduto et al. (2009) and Raes et al. (2009). A review of several studies by Steduto et al. (2011) shows that AquaCrop performed satisfactorily in studies on crop water productivity, soil water balance and biomass production. Specifically, the ability of AquaCrop to simulate soil water dynamics has been reported by Andarzian et al. (2011), Patel et al. (2011), Hussein et al. (2011) and Geerts et al. (2009), among others.

The water productivity (WP) parameter is central to crop growth and water use in AquaCrop. The WP is directly related to biomass production. It embodies the intermediary processes of biomass accumulation and is normalized for reference evapotranspiration and atmospheric $\mathrm{CO}_{2}$ concentration. This normalization makes AquaCrop applicable to different geographic locations, seasons and atmospheric $\mathrm{CO}_{2}$ concentrations (Raes et al., 2009). Adjustment of the WP parameter for atmospheric $\mathrm{CO}_{2}$ concentration is done via the equation below (Raes et al., 2009):

$W P_{a d j}=f_{C O 2} x W P$

$f_{\mathrm{CO} 2}=(\mathrm{Ci} / \mathrm{Co}) /(1+0.000138(\mathrm{Ci}-\mathrm{Co}) \quad$ where

WPadj is the adjusted water productivity parameter; $f_{\mathrm{CO} 2}$ is the correction coefficient for $\mathrm{CO}_{2}$; $\mathrm{Co}$ is the reference atmospheric $\mathrm{CO}_{2}$ (based on observations from Mauna Loa, ppm); $\mathrm{C} i$ is the atmospheric $\mathrm{CO}_{2}$ concentration for year i (ppm)

The WP and crop transpiration control biomass production relative to canopy cover. For unstressed crops, the canopy expands from emergence to full cover following an exponential growth function; but a decay function is applied from full canopy cover to senescence. The duration between full canopy cover and onset of senescence can vary depending on environmental conditions. Between the minimum and maximum effective rooting depth, root deepening is controlled by a root development shape factor, which is also affected or adjusted by tracking water availability or the water stress parameter. AquaCrop simulates crop water productivity and transpiration responses to elevated $\mathrm{CO}_{2}$ concentration via an upward adjustment of the water productivity parameter and a downward adjustment of the crop transpiration coefficient based on evidence from FACE experiments (Vanuytrecht and Raes, 2011; Raes et al., 2009).

The soil sub-model of AquaCrop is designed as a dispersed system for which the analyst can specify up to five different horizons (with different textures and depths) for the soil profile. Based on specified soil types and hydraulic characteristics, the soil sub-model calculates the daily water balance in the root zone using an approach which incorporates the processes of runoff, infiltration, redistribution, deep percolation, capillary rise, uptake, surface evaporation and transpiration (Raes et al., 2009). In doing so, AquaCrop separates soil evaporation from transpiration. From input data (mainly saturated water content, field capacity and permanent wilting point), or by specifying the soil textural class, AquaCrop is able to generate the saturated hydraulic conductivity which is used to generate the curve number for the top horizon (Raes et al., 2009). The curve number is adjusted during simulation runs in response to the water content of the top soil. A drainage function, based on the drainage characteristic 
tau $(\tau)$, is used to simulate drainage inside and the percolation out of a soil layer and to simulate the infiltration of water from rain and/or irrigation. The drainage characteristic is proportional to the saturated hydraulic conductivity for the target layer of soil and represents the daily reduction in water content between saturation and field capacity (Raes et al., 2009). AquaCrop uses an exponential equation that incorporates the saturated hydraulic conductivity and soil textural class information of the lowest layer to estimate the maximum possible capillary rise, considering the water content at the bottom of the specified root zone as a driving force (Raes et al., 2009).

In the current study, the climate and soil data, together with the calibration information based on the genotype Westminster were used to simulate the effect of climate change on potential recharge in the fourteen administrative regions of the UK. The simulations were done for rain-fed conditions and fertility stress was not considered. The initial soil water content for each simulation run was set to field capacity and the hydrogeological conditions below the root zone were not considered. Sowing dates ranged from $13^{\text {th }}$ February (for Eastern England, EE) to $24^{\text {th }}$ March (for Northwest Scotland, NWS) and were within the range of the HGCA recommended sowing dates. Harvests occurred between late June and August, with most occurring in July-August. A detailed description of the entire simulation study has been provided in Yawson (2013).

\section{Data Analysis}

For each region, time slice and emissions scenario, the simulation outputs were imported in Microsoft Excel where the 100 output files (resulting from the 100 model variants) were averaged. The total seasonal rainfall and potential recharge data were then extracted and descriptive statistics and charts were generated for these variables. The potential recharge data for each time slice, region and emissions scenario were imported in Stata version 13 where a factorial analysis of variance (ANOVA) with 'potential recharge' as the dependent variable was done. Contrast analysis was done for the regions using the Tukey HSD test after detecting significance difference in the model for the regions.

\section{RESULTS}

\section{Seasonal Rainfall}

Generally, the seasonal rainfall for the regions did not vary substantially across the time slices for separate emissions scenarios (Figure 2). However, differences were observable between emissions scenarios, and for different regions for each emissions scenario. Under the low emissions scenario (LES) and in the 2030s, Eastern England (EE) had the least mean seasonal rainfall (approximately $233 \mathrm{~mm}$ ) while Northwest Scotland (NWS) had the highest (approximately $608 \mathrm{~mm}$ ) (Figure 2). For each region, the seasonal rainfall increased marginally from the 2030 s to the 2050 s (with few exceptions). Five regions that had the 
lowest mean seasonal rainfall were EE, EM (East Midlands), SEE (South East England), WM (West Midlands) and YH (Yorkshire and Humber). For the medium emissions scenario (MES), EE had the least seasonal rainfall $(240 \mathrm{~mm})$ while Southwest Scotland (SWS) had the highest $(429 \mathrm{~mm})$ in the 2030s (Figure 2). The seasonal rainfall did not vary substantially across the time slices per region. Again, the EE, EM, SEE, WM and YH had low seasonal rainfall. Again, these regions had the least seasonal rainfall under the high emissions scenario (HES) (Figure 2), with EE recording the least $(243 \mathrm{~mm}$ ) and SWS recording the highest (434 $\mathrm{mm}$ ) in the 2030s. Apart from Northwest England (NWE) and Wales (WA), seasonal rainfall changed marginally between the time slices.
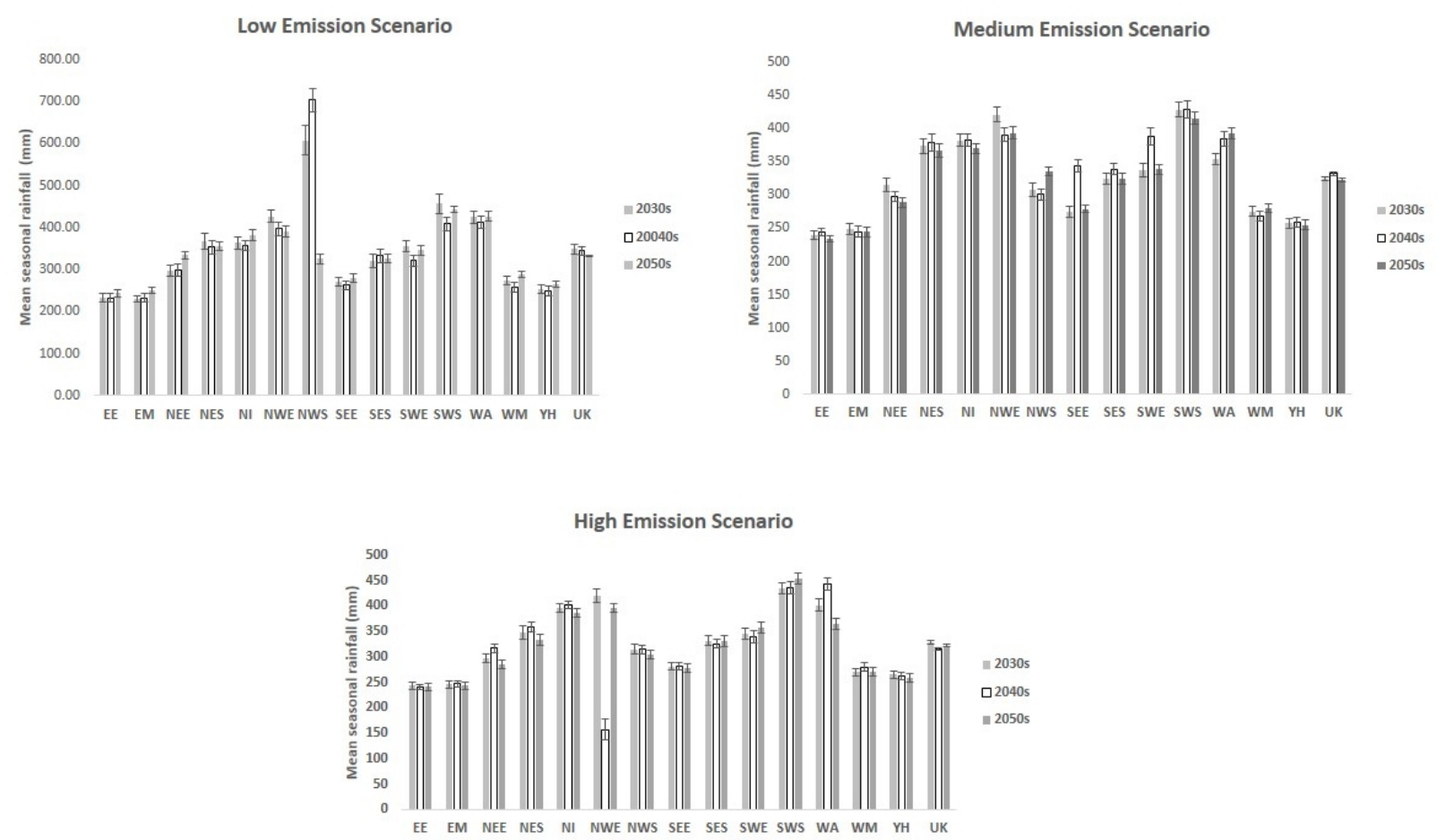

Figure 2: Seasonal rainfall under the three emission scenarios and the three time slices. Error bars are standard errors.

\section{Potential Groundwater Recharge}

Potential recharge under the low emissions scenario is shown in Figure 3. Patterns of increases and decreases over the time slices are observable. For example, the regions that show decreasing trend from the 2030s to the 2050s under the LES include the EE, NES, NWE, SEE, SWE, and YH. The NEE shows an increasing trend while the remaining regions either show a decrease and increase (or vice versa) from the 2030s to the 2050s. Five regions that showed consistently low potential recharge from the 2030s to the 2050s were EE, EM, SEE, WM and YH. The NWS and SWS tended to have the highest potential recharge for the 2030s and 2040s, with the minimum of NWS being higher than most of the other regions. However, in the 2050s, the potential recharge of the regions were comparable apart from the 
five regions with the least potential recharge. It is also noteworthy that the five regions with the least potential recharge also had very compact box plots, indicating little differences between the third and first quartiles.
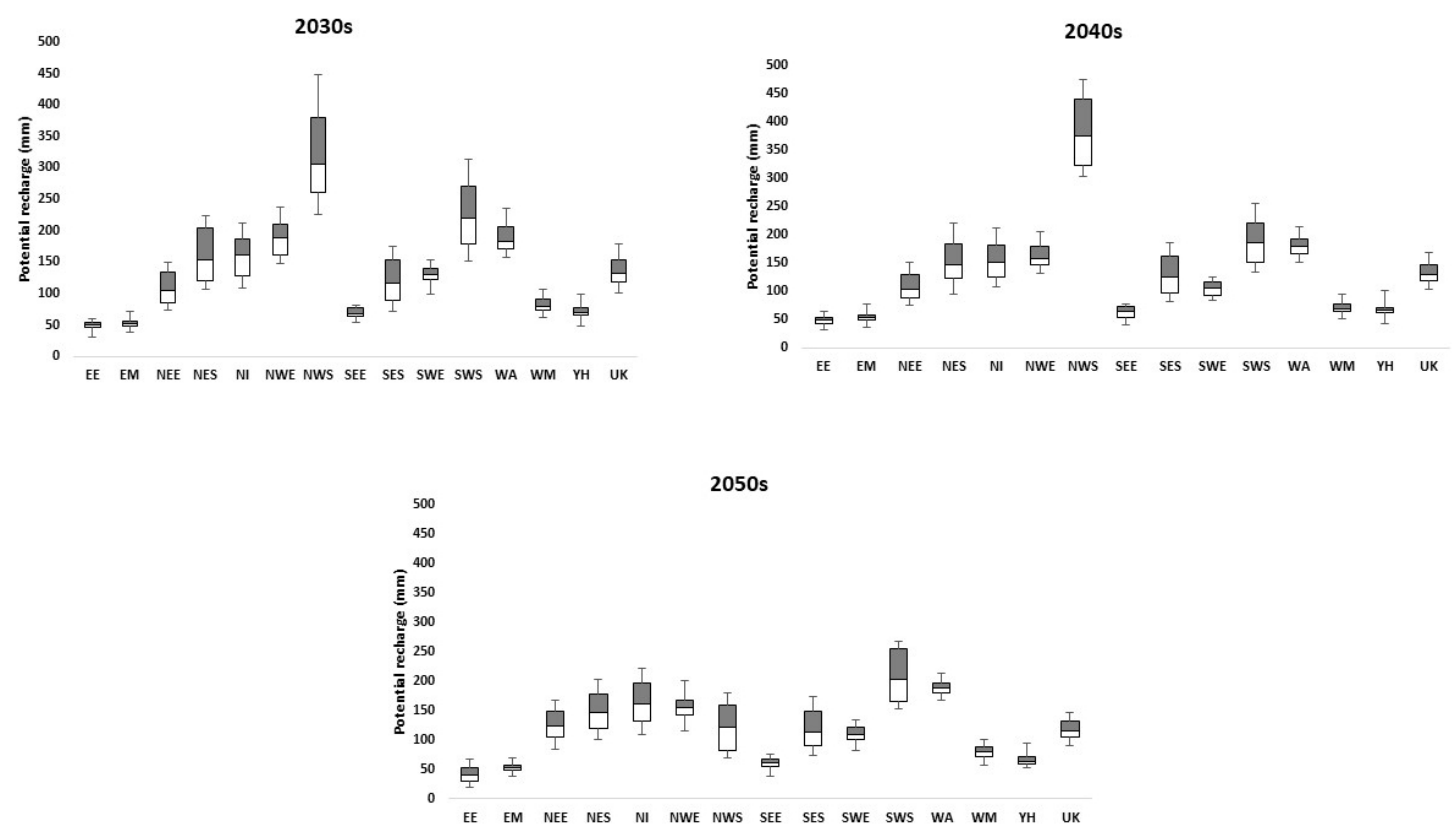

Figure 3: Seasonal potential recharge under the low emission scenario (LES) for the 2030s, 2040s, and 2050s.

For the MES, a similar pattern is observed (Figure 4). However, decreases in potential recharge are observed for most regions. Particularly, the distinctive high values for NWS and SWS observable under the LES reduce to comparable values with other regions under the MES. However, the EE, EM, SEE, WM and YH remain the regions with least potential recharge across the three time slices, except in the 2040s when there is substantial increase in SEE. 


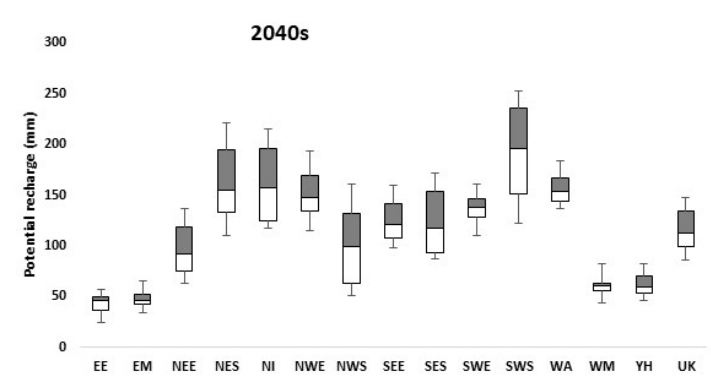

2050s

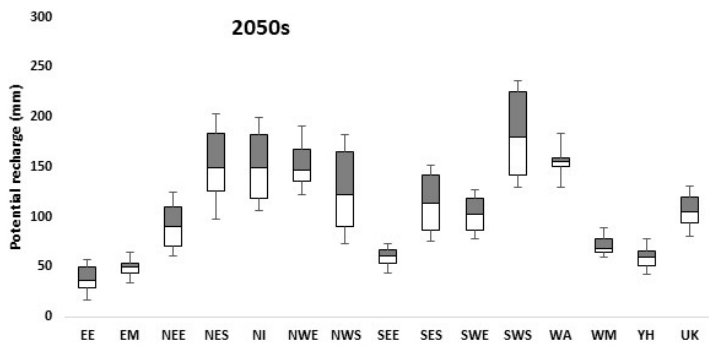

Figure 4: Seasonal potential recharge under the medium emission scenario (MES) for the 2030s, 2040s, and 2050s.

For the HES, a similar pattern of increase and decrease across the time slices were observed (Figure 5). Only NWE and YH showed consistent decrease from the 2030s to the 2050s while SWS, NWS, and WM showed consistent increases from the 2030s to the 2040s. Under this scenario, Northern Ireland (NI) and Southwest Scotland (SWS) had the highest potential recharge from the 2030s to the 2050s. The same five regions with the lowest potential recharge under the other emission scenarios had the least potential recharge under the HES and they retained their compact box plots.
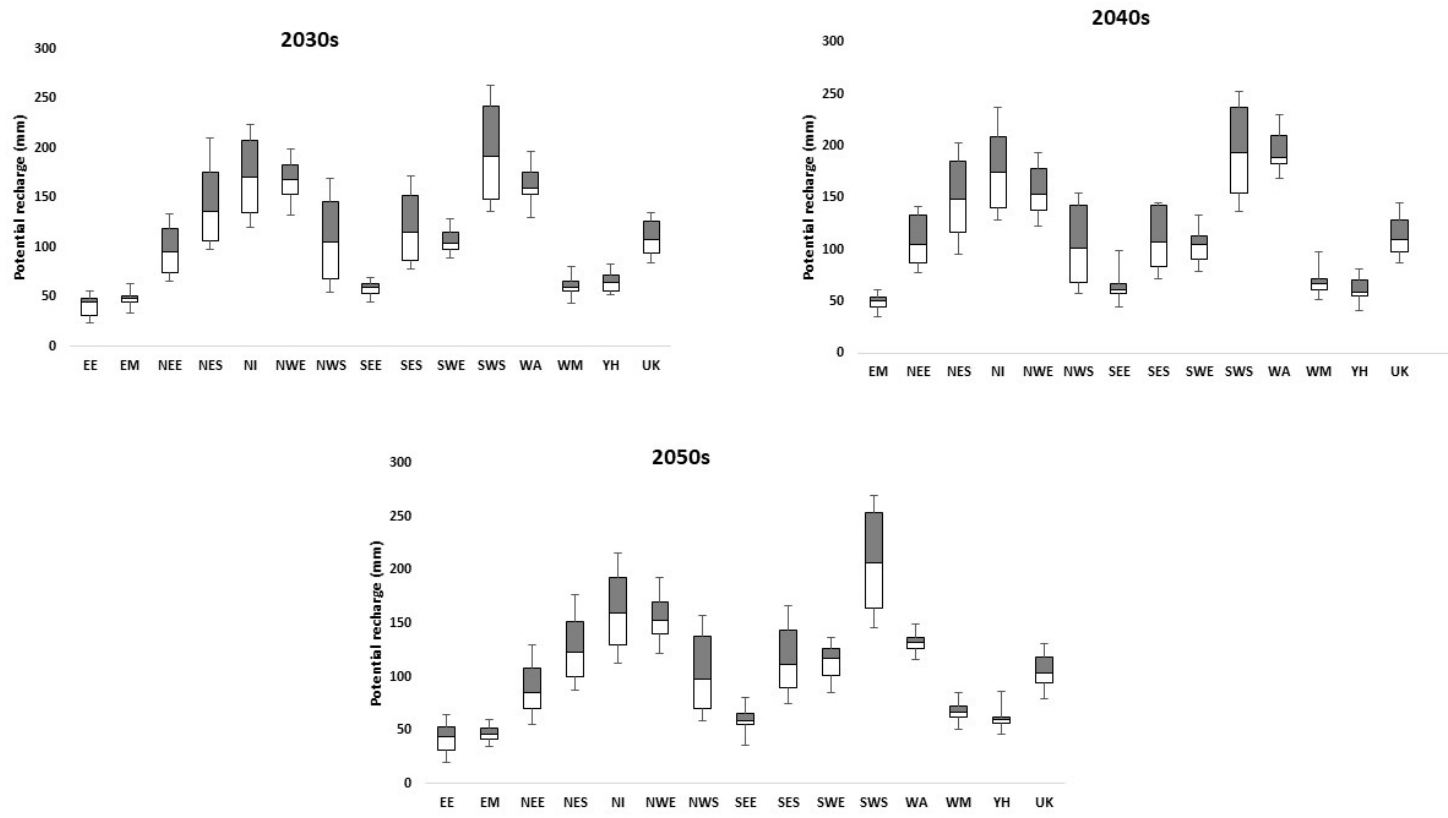
Figure 5: Seasonal potential recharge under the high emission scenario (HES) for the 2030s, 2040s, and 2050s.

\section{Differences between projected and baseline potential recharge}

The differences between projected and baseline potential recharge (mean for the period 19811990) are presented in Figure 6. In the 2030s, seven regions (mostly English regions) show decreased recharge over baselines. The largest reductions are observed in EM, SEE, WM, and YH. The NWS shows reductions under the HES and MES and the same pattern is observed for the UK. The largest reduction for all emissions scenarios was $29 \mathrm{~mm}$ (YH, MES) and the largest increase was approximately $37 \mathrm{~mm}$ (SWS, LES). Similar regional variations in reductions and increases over baseline potential recharge were observed for the 2040 s and 2050s, except that the magnitude of the difference changes. In the 2040s, NWS and SES showed the largest increases (approximately 27 and $28 \mathrm{~mm}$ ) over the baseline values, while WM recorded the largest reductions (up to $38 \mathrm{~mm}$ ) for all emissions scenarios. Similarly, in the 2050s, WM records the largest reduction under the HES $(31 \mathrm{~mm})$ while SWS and WA recorded the largest increase over baseline potential recharge. In all, larger increases in potential recharge across the time slices were observed under the LES, while the largest reductions were observed under the HES.
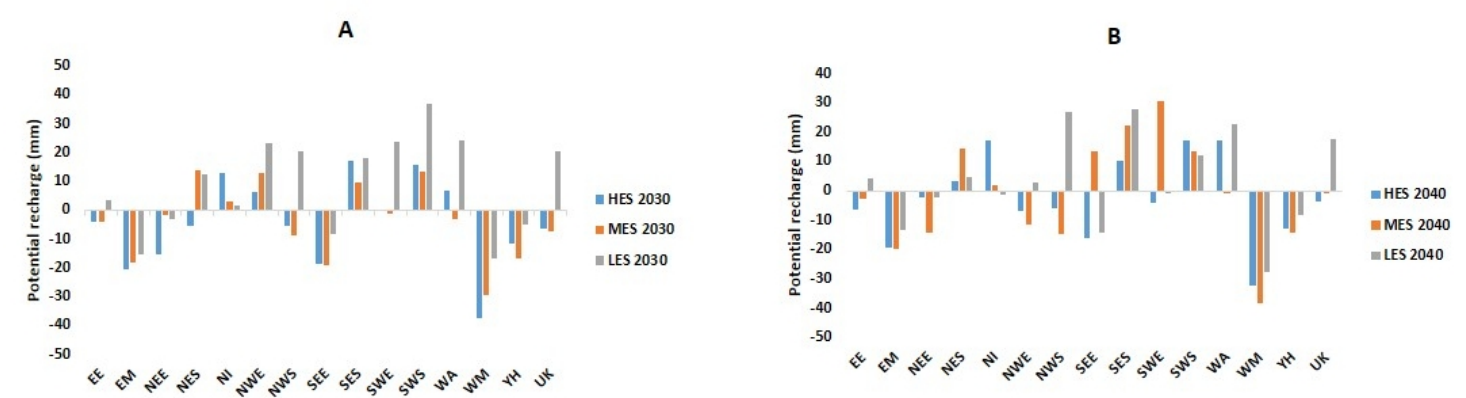

Figure 6: Differences between projected and baseline potential recharge in the (A) 2030s, (B) 2040s, and (C) 2050s.

The analysis of variance (ANOVA) showed no interaction effect between time slice and emissions scenarios. The results were invariant between the sequential and partial sums of squares methods. However, the overall model was significant at $95 \%$ confidence level (Table 
2) as the model accounted for over $70 \%$ of the variance in the potential recharge. The ANOVA of the potential recharge showed that there were significant differences between emissions scenarios and the regions, but not between the time slices. Because the emissions scenarios had only two degrees of freedom, contrast analysis was done only for the regions (Table 3).

Table 2: Analysis of variance of the projected potential recharge.

\begin{tabular}{|l|c|c|c|c|c|}
\hline Source & Seq. SS & df & MS & F & Prob > F \\
\hline Model & 321504 & 17 & 18912.019 & 21.43 & 0.0000 \\
\hline $\begin{array}{l}\text { Emission } \\
\text { Scenario }\end{array}$ & 10507.152 & 2 & 5253.57598 & 5.95 & 0.0035 \\
\hline Time Slice & 2893.9752 & 2 & 1446.9876 & 1.64 & 0.1988 \\
\hline Region & 308103.196 & 13 & 23700.2458 & 26.86 & 0.0000 \\
\hline Residual & 95303.302 & 108 & 882.437982 & & \\
\hline Total & 416807.625 & 125 & 3334.461 & & \\
\hline
\end{tabular}

Table 3: Contrast analysis for UK regions (Tukey HSD test at 95\% Confidence Level)

\begin{tabular}{|c|c|c|c|c|c|c|c|c|c|c|c|c|c|c|}
\hline & $\mathrm{EE}$ & EM & NEE & NES & NI & $\begin{array}{l}\mathrm{NW} \\
\mathrm{E}\end{array}$ & NWS & SEE & SES & SWE & SWS & WA & $\begin{array}{l}\mathrm{W} \\
\mathrm{M}\end{array}$ & $\begin{array}{l}\mathrm{Y} \\
\mathrm{H} \\
\end{array}$ \\
\hline $\mathrm{EE}$ & & & & & & & & & & & & & & \\
\hline EM & 7.69 & & & & & & & & & & & & & \\
\hline NEE & $61.54^{*}$ & $53.85^{*}$ & & & & & & & & & & & & \\
\hline NES & $\begin{array}{l}109.23 \\
*\end{array}$ & $\begin{array}{l}101.54 \\
*\end{array}$ & 47.69 & & & & & & & & & & & \\
\hline NI & $\begin{array}{l}120.05 \\
*\end{array}$ & $\begin{array}{l}112.36 \\
*\end{array}$ & $\begin{array}{l}58.51 \\
* \\
\end{array}$ & 10.82 & & & & & & & & & & \\
\hline $\begin{array}{l}\mathrm{NW} \\
\mathrm{E}\end{array}$ & $\begin{array}{l}121.09 \\
*\end{array}$ & $\begin{array}{l}113.40 \\
*\end{array}$ & $\begin{array}{l}59.54 \\
*\end{array}$ & 11.86 & 1.04 & & & & & & & & & \\
\hline $\begin{array}{l}\mathrm{NW} \\
\mathrm{S}\end{array}$ & $\begin{array}{l}121.36 \\
*\end{array}$ & $\begin{array}{l}113.67 \\
*\end{array}$ & $\begin{array}{l}59.81 \\
* \\
\end{array}$ & 12.13 & 1.31 & 0.27 & & & & & & & & \\
\hline SEE & 25.95 & 18.26 & -35.59 & -83.28 & $\begin{array}{l}94.0 \\
9\end{array}$ & $\begin{array}{l}95.1 \\
4\end{array}$ & 95.41 & & & & & & & \\
\hline SES & $76.09 *$ & $68.40^{*}$ & 14.55 & -33.14 & $\begin{array}{l}- \\
43.9 \\
6\end{array}$ & $\begin{array}{l}- \\
45.0 \\
0\end{array}$ & 45.27 & $50.14 *$ & & & & & & \\
\hline SWE & $70.25^{*}$ & $62.56^{*}$ & 8.71 & -38.98 & $\begin{array}{l}- \\
49.8 \\
0\end{array}$ & $\begin{array}{l}50.8 \\
4\end{array}$ & 51.11 & 44.29 & -5.84 & & & & & \\
\hline SWS & $\begin{array}{l}156.25 \\
*\end{array}$ & $\begin{array}{ll}148.56 \\
*\end{array}$ & $\begin{array}{l}94.71 \\
*\end{array}$ & $\begin{array}{l}47.02 \\
2\end{array}$ & $\begin{array}{l}36.2 \\
0\end{array}$ & $\begin{array}{l}35.1 \\
6\end{array}$ & 34.89 & $\begin{array}{l}130.30 \\
*\end{array}$ & $\begin{array}{l}80.16 \\
* \\
*\end{array}$ & $\begin{array}{l}86.01 \\
* \\
*\end{array}$ & & & & \\
\hline WA & $\begin{array}{l}123.00 \\
*\end{array}$ & $\begin{array}{l}115.31 \\
*\end{array}$ & $\begin{array}{l}61.46 \\
*\end{array}$ & 13.77 & 2.96 & 1.91 & 1.64 & $97.05^{*}$ & 46.91 & $\begin{array}{l}52.76 \\
*\end{array}$ & -33.25 & & & \\
\hline WM & 27.63 & 19.94 & -33.91 & -81.60 & $\begin{array}{l}- \\
92.4 \\
2\end{array}$ & $\begin{array}{l} \\
93.4 \\
6\end{array}$ & $\begin{array}{l}\overline{-} \\
93.73 \\
\overline{-} \\
99.72\end{array}$ & 1.68 & -48.46 & -42.62 & $\begin{array}{l}- \\
128.6 \\
2\end{array}$ & -95.37 & & \\
\hline YH & 21.64 & 13.94 & -39.91 & -87.59 & $\begin{array}{l}- \\
98.4 \\
1\end{array}$ & $\begin{array}{l}99.4 \\
5\end{array}$ & & -4.32 & -54.45 & -48.61 & $2_{2}^{134.6}$ & $\begin{array}{l}-701.3 \\
7\end{array}$ & 5.99 & \\
\hline
\end{tabular}

The contrast analysis of the mean potential recharge showed that, across the emissions scenarios, EE was significantly different from NEE, NES, NI, NWE, NWS, SES, SWE, SWS, and WA (Table 2). The EM was significantly different from all other regions except SEE, WM and YH. In addition to earlier observations, the NEE was significantly different 
from the NI, NWE, NWS, SWS, and WA. Apart from EE and EM, the NES was not significantly different from any other region. Similarly, the NI, NWE and NWS were not significantly different from other regions except EE, EM, and NEE. Overall, the EE and EM were significantly different from nine other regions; the NEE was significantly different from seven other regions; the SWS was significantly different from six other regions while WA was significantly different from five other regions. The SES and SWE were significantly different from four other regions while NES was significantly different from two other regions. The remaining regions were significantly different from three other regions, except WM and YH which were not significantly different from any other region.

\section{DISCUSSION}

\section{Potential Recharge in the Future}

Groundwater remains an important water resource for many countries, including the UK. In the face of climate change, simulation of future trends in potential recharge can support planning and proactive management decisions on groundwater resources (Gemitzi et al., 2017). In the current study, a water-driven model (AquaCrop) was used to simulate potential recharge from spring barley crop fields in the UK under projected climate change, covering the spring-summer season (the period from sowing to harvesting of spring barley). This is important as agriculture covers the largest share of UK land use, with cereals accounting for the largest share of cultivated crops (Defra, 2017). Projected reductions in summer rainfall and increases in warmer temperatures in the UK are centred on June-July-August (Wilby et al., 2010; Jenkins et al., 2009; Murphy et al., 2009). Herrera-Pantoja and Hiscock (2008) studied the effect of climate change on three UK aquifers and showed that the main effect of climate change on potential recharge was evident in the period April-September. These suggest that an understanding of contribution of crop fields to potential recharge during the spring-summer period would be useful for adaptation planning. The current study therefore highlights potential recharge from crop fields (using spring barley) during the spring-summer season in the future.

Projected changes in precipitation due to climate change have larger uncertainties than temperature (Murphy et al., 2009). In the current study, projected mean seasonal rainfall for spring barley did not show substantial variations across the three time slices for a given emissions scenario but there were much variations between the regions and a tendency towards reduction from the LES to the HES. Mainly, the regions in the eastern half of England had the least seasonal rainfall, except West Midlands (WM) which is in the west, and Northeast England (NEE, Figure 2). This observation is consistent with the fact that precipitation in the UK increases from east to west (Murphy et al., 2009). Regardless of the low rainfall in these regions, the barley crop was found to potentially remain viable under the projected climate change in all the UK regions studied (Yawson et al., 2016; Yawson, 2013). 
The quantity (and distribution) of seasonal rainfall has direct relationship with the quantity of water contributed to potential recharge. Often, groundwater recharge is regarded as the vertical flow of water across the water table even though it can include cross-formational flows from adjacent or underlying hydrogeologic formations (Green et al., 2011). In the current study, the pattern of potential recharge for the regions seems to follow the east-west and south-north gradient in rainfall for the UK, as well as the regional differences in the magnitude of mean seasonal rainfall (Figure 2). However, because the mean rainfall for the regions did not vary substantially across the time slices, the observed variations in potential recharge across the time slices could be in response to a variable other than rainfall. While potential recharge is expected to correspond to rainfall patterns, it is not always the case. According to Crosbie et al (2013), studies have shown that increased rainfall intensity, changes in wet/dry spell duration or changes in the time required for annual crops to complete their life cycle might affect variations in potential recharge under different climate change scenario, without a direct relationship with rainfall. Potential recharge is sensitive to both changes in temperature and precipitation (Gemitzi et al., 2017). For example, Gemitzi et al. (2017) showed that a unit change in decadal precipitation resulted in less than $1.5 \%$ change in decadal recharge whereas a unit increase in decadal temperature resulted in up to approximately $11 \%$ decrease in decadal recharge. They reported that future recharge during winter corresponded to projected winter precipitation while spring-summer recharge corresponded more with temperature. Cosbie et al. (2013) reported that a $1 \%$ change in rainfall resulted in $2 \%$ change in recharge for the US High Plains, and reductions in recharge under the warmer scenario was not related to changes in rainfall. This suggests that warming conditions could account for the observed variations in regional potential recharge across the time slices and emissions scenario. This, in turn, suggests that the combination of projected low summer rainfall and warmer temperatures (Murphy et al., 2009) could have grave impacts on potential groundwater recharge or supply at a period when consumptive use of water could be high, especially in the English regions that recorded low potential recharge.

Warmer temperatures operate through evapotranspiration to affect crop growth and potential recharge. In the current study, evapotranspiration, together with the quantity and distribution of rainfall, could account for the observed variations in regional potential recharge (Figure 35). Seasonal crop evapotranspiration (ETc) increased slightly from the 2030s to the 2050s (Appendix 2). In addition, the regions that had low potential recharge had corresponding high seasonal ETc. For example, prominent regions with higher seasonal ETc (but low variability in ETc within a time slice and emissions scenario) included EE, EM, SEE, and SWE (Appendix 2). In the 2050s, under the HES, ETc of EE was suppressed due to faster phenophases and attainment of total thermal time. In the current study, potential recharge was generally highest under the LES and lowest under the HES, an observation that is consistent with previous studies (Gemitzi et al., 2017; Crosbie et al., 2013; Ulbrich, 2003; Richter and Semenov, 2005) that potential recharge can decrease under warmer conditions even if rainfall does not change substantially. This can be due to low evapotranspiration resulting from moderate increase in temperatures together with adequate rainfall under the LES (Ficklin et al., 2009; Murphy et al., 2009) while higher evapotranspiration rates (Appendix 2) would 
account for the relatively lower potential recharge under the HES. For example, under high evapotranspiration conditions and decreasing soil water content, crops create high matric potential in the root zone, potentially resulting in moderate transport of water downwards (Scanlon et al., 2005; Bölke, 2002).

A study by Eckhardt and Ulbrich (2003) showed that slightly warmer temperatures under the LES caused only minute reductions in groundwater recharge, compared to the HES, in the Dill catchment in Germany. Richter and Semenov (2005) reported that, even under projected increase in precipitation, maximum soil moisture deficit in wheat fields in England and Wales will reduce by about $20 \mathrm{~mm}$ due to higher rates of evapotranspiration arising from warmer temperatures. In addition, the average maximum soil water deficit were lower in the west and north compared to the eastern and southern regions. However, they observed that in the 2050s, these differences will narrow as the western regions appeared to be more hydrologically responsive, resulting in larger changes, than in the eastern and southern regions. In the current study, however, the largest reductions for the 2030s were $20 \mathrm{~mm}$ (EM) and $37 \mathrm{~mm}$ (WM) under the HES; $19 \mathrm{~mm}$ (SEE) and $29 \mathrm{~mm}$ (WM) under the MES; $15 \mathrm{~mm}$ (EM) and $16 \mathrm{~mm}$ (WM) under the LES (Figure 6). In the 2050s, the largest reductions were $23 \mathrm{~mm}$ (NEE) and $31 \mathrm{~mm}$ (WM) under the HES; $21 \mathrm{~mm}$ (NEE) and $27 \mathrm{~mm}$ (WM) under the MES; and $16 \mathrm{~mm}$ (SEE) and $19 \mathrm{~mm}$ (WM) under the LES. The results in the current study therefore compare reasonably well with the results of Richter and Semenov (2005), noting that the latter was based on the A1B (or the MES). Further, in the current study, the reductions in potential recharge rather increases in the southern and eastern regions (e.g. EE, EM, SEE, YH) from the 2030s to the 2050s, and from the LES to the HES, due to the ETc gradient (Appendix 2) and soil water depletion which consequently limit potential recharge (Calanca et al., 2006; Scanlon et al., 2005; Arnell, 1998). In the western regions, higher rainfall (Figure 2) saturated the soils (data not shown; see Yawson et al., 2016) and suppressed ETc, resulting in rather higher potential recharge.

For the UK, we did not find a similar study on potential recharge from crop fields at regional scale to allow robust comparison. There is limited information on the contribution of arable crop fields to future potential groundwater recharge even though there have been studies in specific catchments. Jackson et al. (2011) studied the impacts of climate change on a Chalk aquifer in south-central England using an ensemble of 13 global climate models run under the A2 (medium-high) emission scenario for the 2080s. The overall ensemble results ranged from a decrease of $26 \%$ to an increase of $31 \%$ in potential recharge. Ten of the global climate models predicted a decrease while three predicted an increase. Jackson et al. (2011) found little variation in annual recharge but significant variation in seasonal recharge (especially between April and October) and more concentrated recharge during winter. This significant variation in Spring-to-Autumn recharge is important for water resources management and use in relation to potential recharge from arable crop fields, especially in the face of projected low summer rainfall and stream flow (Murphy et al., 2009). In a similar study, HerreraPantoja and Hiscock (2008) assessed the potential groundwater recharge on two catchments in south-east England under the HES. They reported 20\% reduction in potential groundwater 
recharge for sites in East Anglia and 40\% for sites in Sussex. These two studies used catchment models that employ similar soil water balance sub-model. They both used one time slice and one emission scenario. The largest reduction in potential groundwater recharge in the current study was 38\% while the largest increase was approximately $41 \%$ for all regions, time slices and emissions scenarios. Thus, the results in the current study compares well with the catchment-based results. The added value in the current study is that it is based on contribution to potential recharge from arable crop fields and multiple regions, time slices and emissions scenarios. Hence, the current results can feed into land use and agricultural land management practices and decisions to influence potential recharge in the future.

Arnell (1998) noted that, in the UK, groundwater is largely recharged by winter precipitation after satisfying soil deficits and before they begin to develop again in spring. While this might suggest that projected increases in winter precipitation (Murphy et al., 2009; Arnell, 2004) will sufficiently increase groundwater recharge, the rate of evaporation can have a controlling effect. Thus, a higher evaporation rate would likely reduce the length of the recharge season and thereby diminish the effect of higher winter rainfall (Arnell, 1998). This, together with projected low summer rainfall and related soil water deficits (Calanca et al., 2006), makes potential spring-summer recharge a crucial supplement to groundwater especially in southern and eastern England. To this end, the contribution from arable crop fields would equally be important, feeding into land use and water management decisions and practices. Results of the current study suggest that the EE, EM, SEE, WM and the YH will have low contribution to potential groundwater recharge from arable crop fields. Another implication is that postharvest soil water deficits in these regions might be high and, thus, further reducing the quantity or increasing the duration of winter recharge. The results of the ANOVA and contrast analysis show that the EE and EM should be particularly watched for these conditions, followed by the NEE and SEE. Conversely, in some regions (e.g. Scottish regions), large additions to groundwater during the spring-summer season, and residual postharvest soil water content prior to winter might be undesirable as this can contribute to flooding. In the current study, the Scottish regions (especially the SWS), Wales and Northern Ireland had relatively larger contributions to potential groundwater recharge. It was also observed in the simulations that these regions frequently suffered from soil saturation (Yawson, 2013). These areas are worthy of monitoring for saturated conditions and potentially, flooding events during high winter precipitation and intense spring-summer rainfall (Arnell, 1998). The results also suggest that agricultural operations (especially those related to tillage) have to be carefully considered and timed in the future as part of adaptation planning in response to potentially excessive soil saturation. The ANOVA and contrast analysis suggest that SWS, NWS, NI, and WA should be given attention for these conditions. These conditions, of course, would also be influenced by the type and hydraulic properties of the soils, their spatial variations and how they are managed.

\section{Implications for water resource management}


In the UK, climate change is projected to cause warmer and shorter wetter winters, and hotter and longer drier summers, but the impact of lower summer flows is expected to be greater in England and Wales (Arnell, 2004). The Environment Agency (2010) reported that, by 2050, there could be $50 \%$ reduction in river flows during summer due to climate change, and up to $80 \%$ in other areas. However, winter flows could increase by about $15 \%$ over a shorter period. Water scarcity is already an issue in England and Wales (Charlton and Arnell, 2011; Royal Geographical Society with IBG, 2012) where groundwater contributes substantially to public water supply in urban and rural areas, agriculture, electricity and industrial uses (Hiscock, 2005). Irrigated horticulture (which occurs largely in the driest period - summer) has increased substantially in these two regions for the past two decades (Knox et al., 2010). The Environment Agency recently indicated that only 16\% of all horticultural holdings in England and Wales were within catchments where additional abstraction licenses could be possible during summer low flows, 59\% were within over-licensed (water-stressed) catchments, and $20 \%$ were within over-abstracted (water-scarce) catchments, while $35 \%$ of holdings irrigated by mains water were within zones which were seriously water-stressed. Charlton and Arnell (2011) assessed the 25-year Water Resources Management Plans (WRMPs), released by water companies in England and Wales in 2008. They found that climate change had the largest effect on potential reductions in supply, with impacts ranging from no reductions in deployable output to more than $50 \%$ for the individual resource zones assessed. Climate change significantly reduced the deployable output of 44 out of the 68 resource zones, with 35 suffering severe impacts. Clearly, understanding trends in future spring-summer potential recharge from crop fields as a complement to groundwater recharge from other areas is important for adaptive and proactive groundwater management.

For six regions (EE, EM, NEE, SEE, WM, and YH) in the current study, future reductions in potential recharge over baselines were consistent for the time slices and emissions scenarios. Given that agriculture has the largest share of UK land area and cereals having the largest share of cultivated land area, the results of the current study has direct implications for land use and agricultural land management in relation to groundwater resources management in the UK. Particularly, the conversion of crop fields to other uses and land management practices that lower potential recharge in England should be discouraged. In regions with large reductions in potential recharge, arable crop fields could be maintained to augment groundwater recharge while improving infiltration. Here, planned and controlled withdrawal is necessary while alternative supplies or mitigating measures are sought to balance expected increase in demand. Water managers can work with agronomists to identify and improve infiltration in areas that can contribute substantially to potential recharge. For regions where maintenance of base flow is becoming a challenge, it would be important to put even more controls on groundwater depletion in the spring-summer period in the future to help maintain or improve water levels (Crosbie et al., 2013).

In the current study, Wales recorded increases in potential recharge over baseline values, indicating a potential to reduce the water stresses in Wales. In the regions that consistently recorded increase in potential recharge over the time slices and emission scenarios, drainage 
systems might be necessary to reduce the magnitude or duration of soil saturation, potentially mitigate flood risks (for example in Scottish regions) and maintain crop production. It should be noted, however, that this study assessed the future contribution to potential groundwater recharge from spring barley crop fields in the fourteen UK administrative regions. It did not assess actual groundwater storage, which takes much longer time to build up. Proportion of potential recharge that contributes to actual storage might also vary due to losses. This study did not consider topographic effects and changes in soil management practices which can influence the spatial and temporal magnitude of potential recharge.

\section{ASSUMPTIONS AND LIMITATIONS}

Studies on the effects of projected climate change on potential groundwater recharge often have large uncertainties and are further limited by the underlying assumptions. In the current study, potential recharge from barley crop fields under projected climate change was investigated. Based on the circumstances at the time of the study, several assumptions were made that limit the study. Each region was represented with the same soil type and crop. Spatially, soils vary considerably over short distances and, at coarse scale, a mapping unit will typically contain more than one type of soil. In this study, soil properties were derived as the average properties of soil mapping units (SMU) constituting the dominant soil in a given region according to the SINFO Database (Baruth et al., 2006). Given the importance of soil hydraulic properties for potential recharge, the results in the current study provide an impression of potential direction of change even though the magnitude of change in potential recharge could only be indicative. Spatio-temporal changes in soil properties were not considered and optimal conditions of soil fertility were assumed. Soil fertility can affect crop water use and thereby potential recharge. Artificial drainage was also not considered. A spatially explicit study, with soil data at sub-regional spatial scale, could yield a different result. Next, several spring barley genotypes or varieties are grown within each UK region. These genotypes or varieties, even though could have similar water use under adequate soil water supply (Yawson, 2013), would have different water use and therefore different effects on potential recharge under projected climates. However, it was important to use one genotype (Westminster) as a test or representative crop to make the study less complicated. Finally, the current study considered only potential recharge within the barley crop season from spring to summer under the projected climates. It is recognized that winter recharge is crucial for groundwater. However, due to projected conditions during summer periods, it is important to have an indication of the magnitude and direction of change in potential recharge from sowing time in spring when the soils are at field capacity to harvest in summer. Simulating the effect of climate change on potential recharge from barley crop fields in both winter and spring would have required much more parameters (e.g. pre-sowing and postharvest field management parameters between winter and spring), complication, and work than circumstances could permit. Based on these limitations, the results in the current study are applicable to spring-sown barley crop fields, with genotype Westminster, and on the representative soil types used. 


\section{CONCLUSIONS}

The UK is projected to have hotter and drier summer conditions, with adverse implications for summer flows in England and Wales. In the UK, groundwater crucially supports public water supply, agricultural and industrial water uses, especially in England and Wales where water stresses during summer is a major concern. Crop fields contribute to potential recharge (water that drains or percolates from the unsaturated root zone to the underlying saturated zone). To contribute to understanding of the effect of projected climate change on potential recharge from crop fields and to support adaptive management responses with regards to groundwater resources and agronomic practices, this study assessed the contribution of spring barley crop fields to potential groundwater recharge under projected climate change in the fourteen administrative regions of the UK. The results show regional variations in potential groundwater recharge under the three emissions scenarios and time slices considered. The results show that Southwest Scotland (SWS), Northwest Scotland (NWS), Northern Ireland (NI), and Wales (WA) will have large increases in potential recharge from spring barley crop fields, while Eastern England (EE), East Midlands (EM), Northeast England (NEE), Southeast England (SEE), West Midlands (WM) and Yorkshire and Humber (YH) would have the largest reductions in potential recharge. Largely, the reductions or increases in potential recharge over baseline values were consistent across the time slices for each emission scenario, indicating less uncertainty across the time slices. Higher and less variable crop evapotranspiration was a major driver of the observed reductions in potential recharge. Within the limits of the current study, the results provide an indication of the direction of changes in potential recharge from spring barley crop fields. Practically, the results indicate potential changes that can be introduced in the groundwater recharge regime as a result of changing potential recharge from crop fields. While water demand and abstraction could be high during summer, the results show that in some regions, diffuse potential recharge from crop fields will reduce due mainly to higher rates of evapotranspiration. This has implication for the planning and management of groundwater abstraction or depletion and measures to augment groundwater resources to respond to potentially higher demands. For the regions that showed large increases in future potential recharge, adaptive agronomic management responses would include consideration of drainage to avoid excessive and or prolonged soil saturation. Overall, the results indicate possible alterations in future groundwater recharge due to direct effects of changes in crop evapotranspiration rates and rainfall on potential recharge from spring barley crop fields in the UK. Further studies are required to fully quantify the effect of these changes on potential recharge throughout the year, incorporating both spring and winter barley.

\section{Acknowledgment}

This work was part of a $\mathrm{PhD}$ study jointly sponsored by the Centre for Environmental Change and Human Resilience (CECHR, University of Dundee), The James Hutton Institute (JHI) and the University of Cape Coast (Ghana), and was supported by the Rural and 
Environment Science and Analytical Services Division (RESAS) of the Scottish Government through Work packages 3.3 and the Centre of Expertise in Climate Change (2011-2016).

\section{References}

Andarzian, B., Bannayan, M., Steduto, P., Mazraeh, H., Barati, M.E., Barati, M.A., Rahnama, A., 2011. Validation and testing of the AquaCrop model under full and deficit irrigated wheat production in Iran. Agr. Water Manage. 100, 1-8.

Arnell, N.W., 2004. Climate change and global water resources: SRES emissions and socioeconomic scenarios. Global Environmental Change 14(1), 31-52.

Arnell, N.W., 1998. Climate change and water resources in Britain. Climatic Change 39, 83110 .

Baruth, B., Genovese, G., Montanarella, L., 2006. New soil information for the MARS Crop Yield Forecasting System. European Commission Directorate General, Joint Research Centre, Ispra, Italy.

Bölke, J-K., 2002. Groundwater recharge and agricultural contamination. Hydrogeology Journal 10 (1), 153-179.

Calanca, P., Roesch, A., Jasper, K., Wild, M., 2006. Global warming and the summertime evapotranspiration regime of the alpine region. Climatic Change 79(1-2), 65-78.

Charlton, M.B., Arnell, N.W., 2011. Adapting to climate change impacts on water resources in England - an assessment of draft water resources management plans. Global Environmental Change, 21, 238-248.

Crosbie, R.S., Scanlon, B.R., Mpelasoka, F.S., Reedy, R.C., Gates, J.B., Zhang, L., 2013. Potential climate change effects on groundwater recharge in the High Plains Aquifer, USA. Water Resources Research 49, 3936-3951.

Defra (2017). Agriculture in the United Kingdom 2016. Department of Environment, Food and Rural Affairs (Defra), London, pp.110. https://assets.publishing.service.gov.uk/government/uploads/system/uploads/attachment_data /file/672119/AUK-2016-08jan18.pdf (accessed May 25, 2018)

Eckhardt, E., Ulbrich, U., 2003. Potential impacts of climate change on groundwater recharge and streamflow in a central European low mountain range. J. Hydrol. 284, 244-252.

Ficklin, D.L., Luo, Y., Luedeling, E., Zhang, M., 2009. Climate change sensitivity assessment of a highly agricultural watershed using SWAT. J. Hydrol. 374, 16-29.

Geerts, S., Raes, D., Gracia, M., Miranda, R., Cusicanqui, J.A., Taboada, C., Mendoza, J., Huanca, R., Mamani, A., Condori, O., Mamani, J., Morales, B., Osco, V., Steduto, P., 2009. 
Simulating yield response of Quinoa to water availability with AquaCrop. Agron. J. 101, 499-508.

Gemitzi, A., Ajami, H., Richnow, H-H., 2017. Developing empirical monthly groundwater recharge equations based on modeling and remote sensing data - modeling future groundwater recharge to predict potential climate change impacts. Journal of Hydrology 546, $1-13$.

Giordano, M., 2009. Global groundwater? Issues and solutions. Annu. Rev. Environ. Resour. 34(7), 1-26. doi: 10.1146/annurev.environ.030308.100251

Green, T.R., Taniguchi, M., Kooi, H., Gurdak, J.J., Allen, D.M., Hiscock, K.M., Treidel, H., Aureli, A., 2011. Beneath the surface of global change: impacts of climate change on groundwater. J. Hydrol. 405, 532-560.

Herrera-Pantoja, M., Hiscock, K.M., 2008. The effects of climate change on potential groundwater recharge in Great Britain. Hydrol. Process. 22(1), 73-86.

Hiscock, K., 2005. Hydrogeology: principles and practice. Blackwell Publishing, Oxford, UK, ch.1, pg.10.

Holman, I.P., Tascone, D., Hess, T.M., 2009. A comparison of stochastic and deterministic downscaling methods for modelling potential groundwater recharge under climate change in East Anglia, UK: implications for groundwater resource management. Hydrogeology Journal 17, 1629-1641. doi: 10.1007/s10040-009-0457-8

Hussein, F., Janat, M., Yakoub, A., 2011. Simulating cotton yield response to deficit irrigation with the FAO AquaCrop model. Spanish Journal of Agricultural Research, 9(4), 1319-1330.

IPCC., 2007. Climate change 2007: synthesis report. An assessment of the Intergovernmental Panel on Climate Change, IPCC Plenary XXVII, Valencia, Spain, November 12-17, 2007, 52p. http://www.ipcc.ch/pdf/assessment-report/ar4/syr/ar4_syr.pdf (accessed: May 30, 2011).

Jackson, C.R., Meister, R., Prudhomme, C., 2011. Modelling the effects of climate change and its uncertainty on UK Chalk groundwater resources from an ensemble of global climate model projections. J. Hydrol. 399, 12-28.

Jenkins, G.J., Murphy, J.M., Sexton, D.M.H., Lowe, J.A., Jones, P., Kilsby, C.G., 2009. UK climate projections: briefing report. Met Office Hadley Centre, Exeter, UK.

Jones, P.D., Kilsby, C.G., Harpham, C., Glenis, V., Burton, A., 2009. UK climate projections science report: projections of future daily climate for the UK from the Weather Generator. University of Newcastle, UK. ISBN 978-1-906360-06-1.

Jyrkama, M.I., Sykes, J.F., 2007. The impact of climate change on spatially varying groundwater recharge in the grand river watershed (Ontario). J. Hydrol. 338(3-4), 237-250. 
Knox, J.W., Rodriguez-Diaz, J.A., Weatherhead, E.K., Kay, M.G., 2010. Development of a water-use strategy for horticulture in England and Wales - a case study. Journal of Horticultural Science and Biotechnology, 85(2), 89-93.

Kovalevskii, V.S., 2007. Effect of climate change on groundwater. Water Resources 34 (2), 140-152.

Kruger, A., Ulbrich, U., Speth, P., 2001. Groundwater recharge in Northrhine-Westfalia predicted by a statistical model for greenhouse gas scenarios. Phys. Chem. Earth (B) 26, 853861.

Mileham, L., Taylor, R., Thompson, J., Todd, M., Tindimugaya, C., 2008. Impact of rainfall distribution on the parameterisation of a soil-moisture balance model of groundwater recharge in equatorial Africa. J. Hydrol. 359, 46-58.

Murphy, J.M., Sexton, D.M.H., Jenkins, G.J. et al., 2009. UK climate projections science report: climate change projections. Met Office Hadley Centre, Exeter. ISBN 978-1-906360$02-3$.

Patel, N., Kumar, P., Singh, N., 2011. Performance evaluation of AquaCrop in simulating potato yield under varying water availability conditions. Available online at http://www.rid.go.th/thaicid/_6_activity/Technical-Session/SubTheme2/2.16-Neelam_PP_Kumar-Neetu_S.pdf (accessed March 19, 2012).

Raes, D., Steduto, P., Hsiao, T.C., Fereres, E., 2009. AquaCrop - The FAO crop model to simulate yield response to water: II. Main algorithms and software description. Agron. J. 101, 438-447.

Richter, G.M., Semenov, M.A., 2005. Modelling impacts of climate change on wheat yields in England and Wales: assessing drought risks. Agricultural Systems 84, 77-97.

Royal Geographical Society, 2012. Water policy in the UK: the challenges. RGS-IBG Policy Briefing.

Scanlon, B.R., Keese, K.E., Flint, A.L., Flint, L.E., Gaye, C.B., Edmunds, W.M., Simmers, I., 2006. Global synthesis of groundwater recharge in semiarid and arid regions. Hydrological Processes 20, 3335-3370. doi: 10.1002/hyp.6335

Scanlon, B.R., Reedy, R.C., Stonestrom, D.A., Prudic, D.E., Deennehy, K.F., 2005. Impact of land use and land cover change on groundwater recharge and quality in the southwestern US. Global Change Biology, 11 (10), 1577-1593.

Siebert, S., Burke, J., Faures, J.M., Frenken, K., Hoogeveen, J., Döll, P., Portmann, F.T., 2010. Groundwater use for irrigation - a global inventory. Hydrological Earth System Science 14, 1863-1880. doi:10.5194/hess-14-1863-2010. 
Steduto, P., Hsiao, T.C., Raes, D., Fereres, E., 2009. AquaCrop - The FAO crop model to simulate yield response to water: I. Concepts and underlying principles. Agron. J. 101, 426437.

Steduto, P., Hsiao, T.C., Raes, D., Fereres, E., Izzi, G.G., Heng, L., Hoogeveen, J., 2011. Performance review of AquaCrop - the FAO crop-water productivity model. ICID $21 \mathrm{st}$ International Congress on Irrigation and Drainage, 15-23 October, 2011, Tehran, Iran.

Thenkabail, P.S., Hanjra, M.A., Dheeravath, V., Gumma, M., 2010. A holistic view of global croplands and their water use for ensuring global food security in the 21st Century through advanced remote sensing and non-remote sensing approaches. Remote Sensing, 2(1), 211261.

UNESCO, 2008. Groundwater Resources Assessment under the Pressures of Humanity and Climate Change (GRAPHIC): a framework document. GRAPHIC Series No.2. United Nations Educational, Scientific, and Cultural Organization (UNESCO), Paris, 31 pp.

Vanuytrecht, E., Raes, D. (2011). Assessment of the ' $\mathrm{CO}_{2}$ fertilization effect' on crops with the AquaCrop model. Geophysical Research Abstracts, 13, EGU2011-5917-2, 2011, https://meetingorganizer.copernicus.org/EGU2011/EGU2011-5917-2.pdf (accessed May 28, 2018).

Wilby, R.L., Orr, H., Watts, G. et al., 2010. Evidence needed to manage freshwater ecosystems in a changing climate: turning adaptation principles into practice. Science of the Total Environment, 408, 4150-4164.

Yawson, D.O., Mulholland, B.J., Ball, T., Adu, M.O., Mohan, S., White, P.J., 2017. Effect of climate and agricultural land use changes on UK feed barley production and food security to the 2050s. Land 6, 74, 14 pp. doi:10.3390/land6040074

Yawson, D.O., Ball, T., Adu, M.O., Mohan, S., Mulholland, B.J., White, P.J., 2016. Simulated regional yields of spring barley in the United Kingdom under projected climate change. Climate 4, 54, $21 \mathrm{pp}$. doi:10.3390/cli4040054.

Yawson, D.O., Mulholland, B., Ball, T., Mohan, S., White, P., 2013. Food security in a water-scarce world: making virtual water compatible with crop water use and food trade. Scientific Papers Series Management, Economic Engineering in Agriculture and Rural Development, 13(2), 431-443. ISSN 2284-7995, E-ISSN 2285-3952.

Yawson, D.O., 2013. Climate Change and Virtual Water: Implications for UK Food Security. Ph.D. Thesis, University of Dundee, Dundee, UK, 2013, available at https://discovery.dundee.ac.uk/en/studentTheses/climate-change-and-virtual-water 
Figure 1: A map of the fourteen UK administrative regions.

Figure 2: Seasonal rainfall under the three emission scenarios and the three time slices. Error bars are standard errors.

Figure 3: Seasonal potential recharge under the low emission scenario for the 2030s, 2040s, and 2050s.

Figure 4: Seasonal potential recharge under the medium emission scenario for the 2030s, 2040s, and 2050s.

Figure 5: Seasonal potential recharge under the high emission scenario for the 2030s, 2040s, and 2050s.

Figure 6: Differences between projected and baseline drainage in the (A) 2030s, (B) 2040s, and (C) 2050s 
Appendix 2: Seasonal crop evapotranspiration (ETC)

a. Seasonal ETc for the low emission scenario (LES)

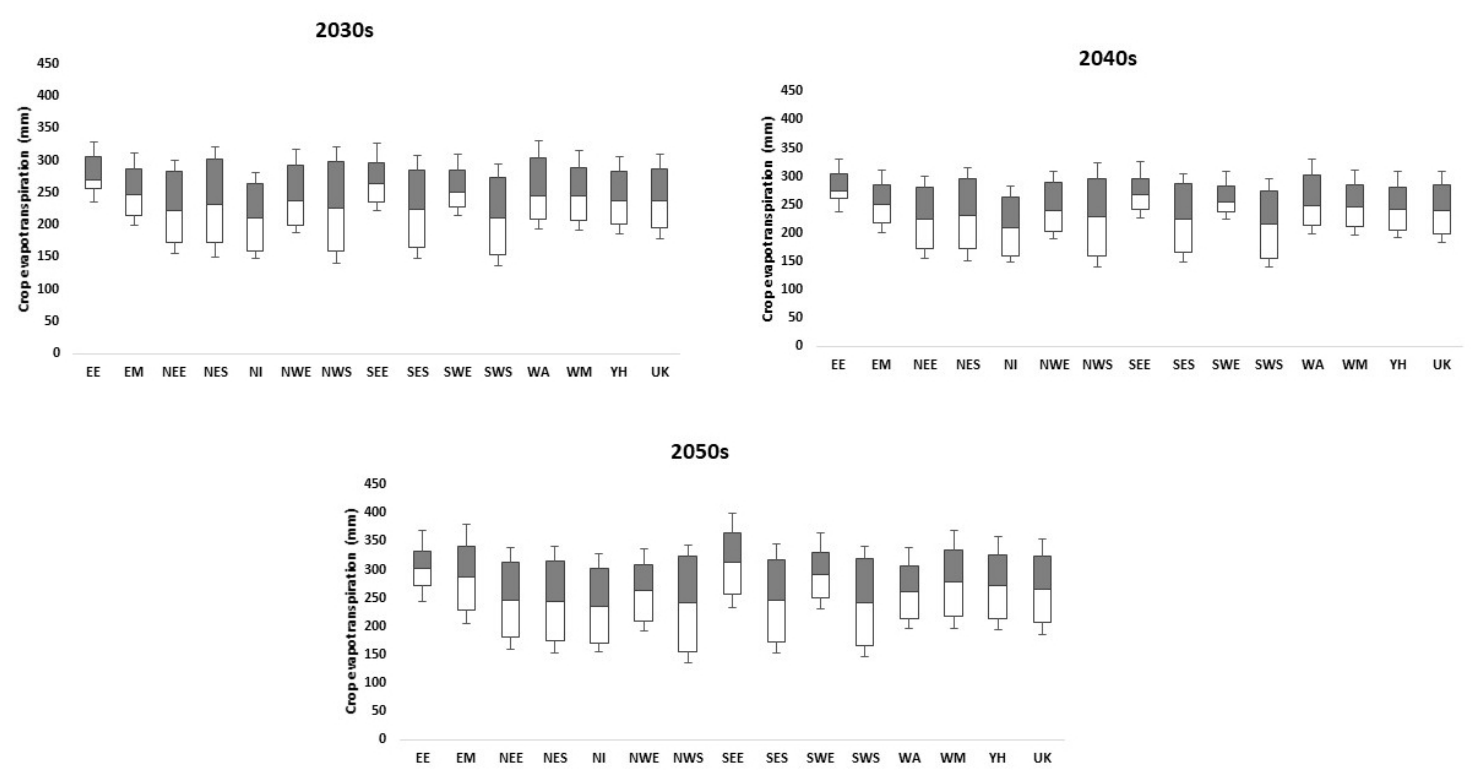


b. Seasonal ETc for the medium emission scenario (MES)
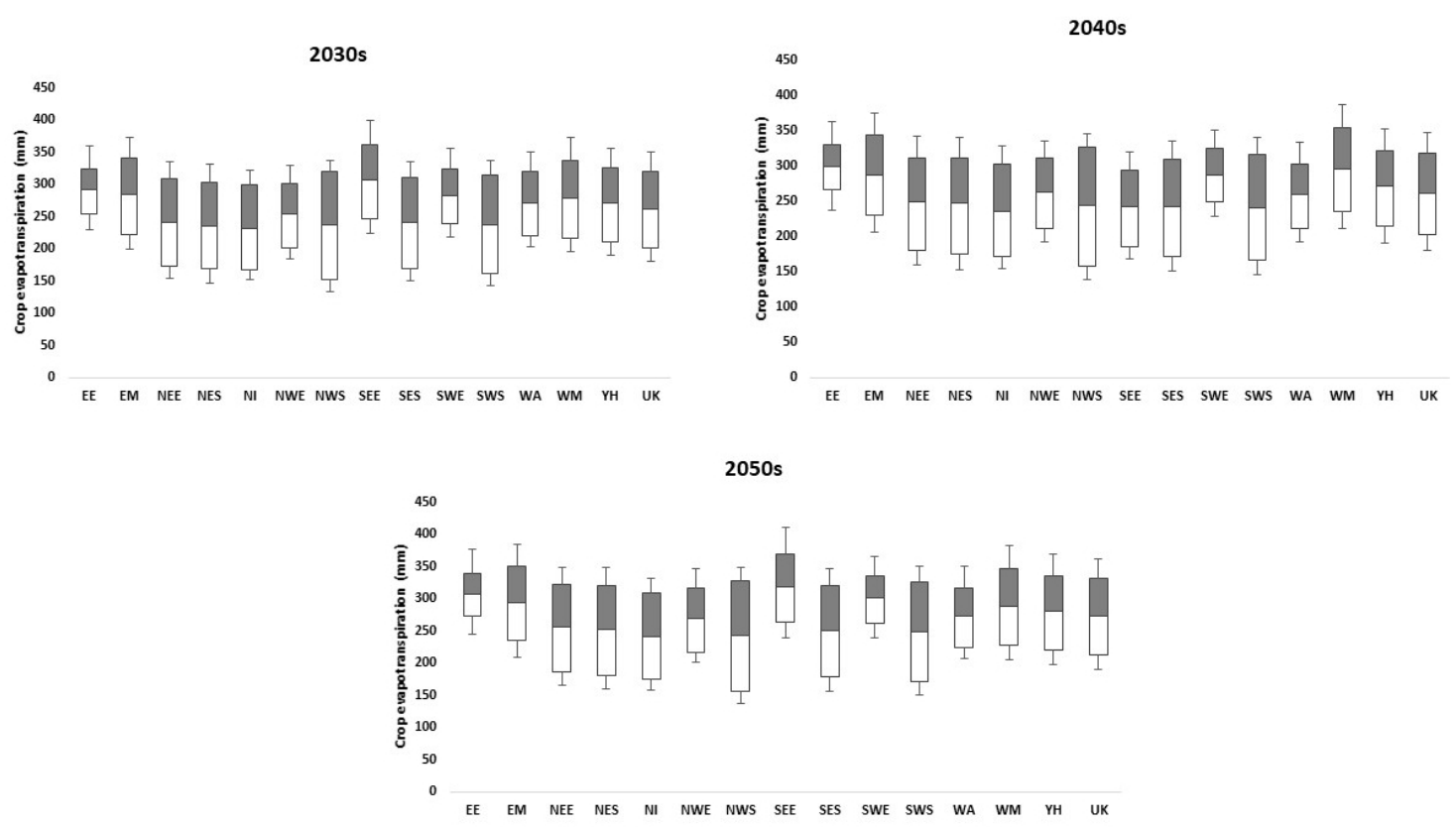
c. Seasonal ETc for the high emission scenario (HES)

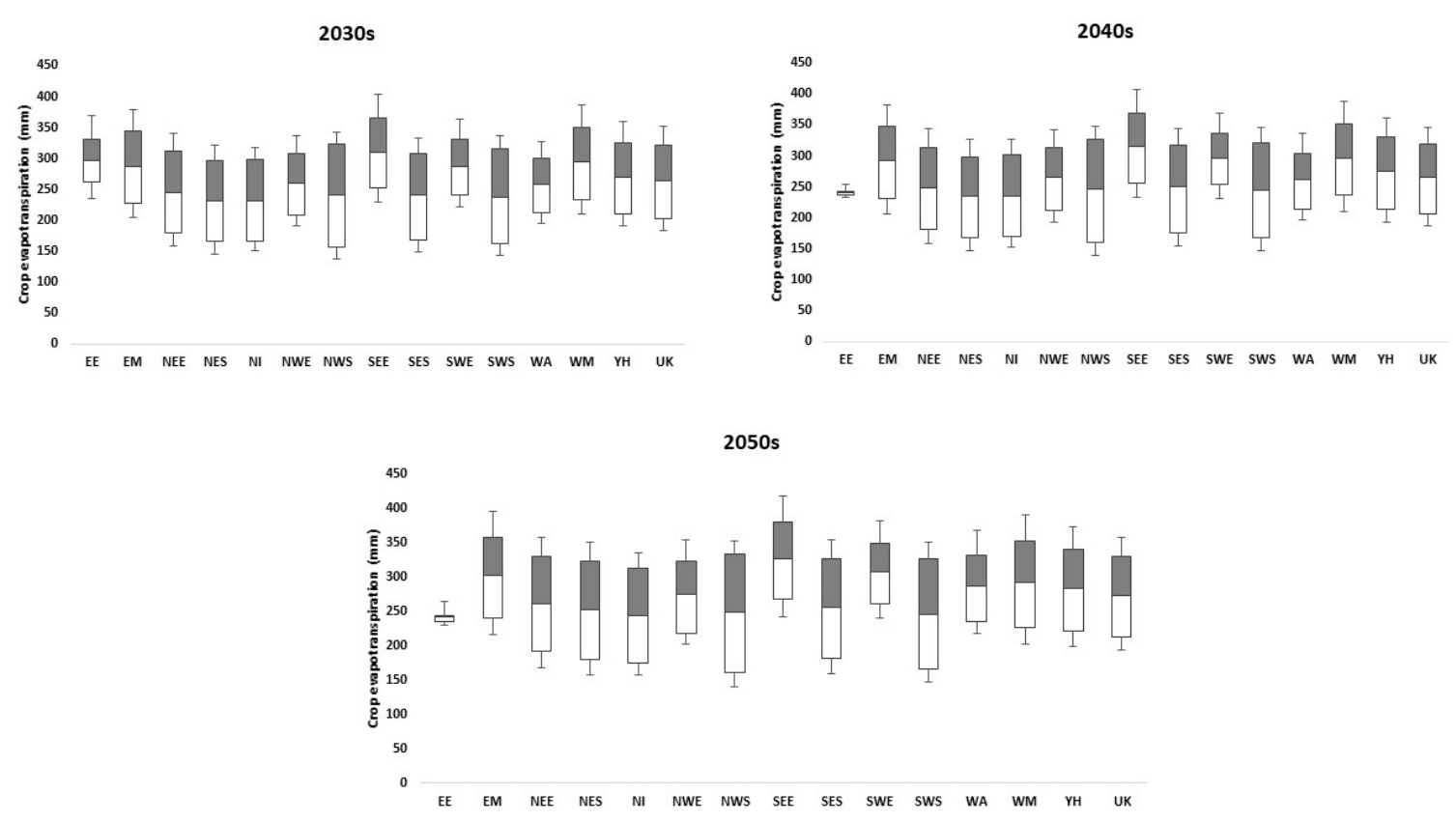


Appendix 1

a. Crop parameter values for barley genotype Westminster used for the simulations

\begin{tabular}{|c|c|c|}
\hline Symbol & Parameter Description & Value \\
\hline \multicolumn{3}{|c|}{ 1. Crop Phenology } \\
\hline \multicolumn{3}{|c|}{ 1.1 Development of green canopy cover (CC) } \\
\hline \multirow[t]{2}{*}{$\mathrm{CC}_{\mathrm{o}}$} & Initial canopy cover (\%) & 3.6 \\
\hline & Time from sowing to emergence (days) & 15 \\
\hline CGC & Canopy growth coefficient (fraction per day, $\%$ day $^{-1}$ ) & 10 \\
\hline $\mathrm{CC}_{\mathrm{x}}$ & Maximum canopy cover (\%) & 85 \\
\hline CDC & Canopy decline coefficient (fraction per day, $\%$ day $^{-1}$ ) & 8 \\
\hline \multicolumn{3}{|c|}{ 1.2 Development of root zone } \\
\hline $\mathrm{Zn}$ & Minimum effective rooting depth $(\mathrm{m})$ & 0.30 \\
\hline \multirow[t]{2}{*}{$Z x$} & Maximum effective rooting depth (m) & 0.70 \\
\hline & Shape factor describing root zone expansion & 1.5 \\
\hline \multicolumn{3}{|c|}{ 2. Crop Transpiration } \\
\hline \multirow[t]{3}{*}{$\mathrm{KC}_{\mathrm{Tr}, \mathrm{x}}$} & Crop coefficient at maximum CC & 1.15 \\
\hline & Decline of crop coefficient $\left(\%\right.$ day $\left.^{-1}\right)$ due to ageing & 0.15 \\
\hline & $\begin{array}{l}\text { Effect of canopy shelter on surface evaporation in late } \\
\text { season stage (\%) }\end{array}$ & 50 \\
\hline \multicolumn{3}{|c|}{ 3. Biomass production and yield formation } \\
\hline \multicolumn{3}{|c|}{ 3.1 Crop water productivity } \\
\hline \multirow[t]{2}{*}{ WP* } & Water productivity normalized for $\mathrm{ET}_{\mathrm{o}}$ and $\mathrm{CO}_{2}\left(\mathrm{~g} \mathrm{~m}^{-2}\right)$ & 15 \\
\hline & $\begin{array}{l}\text { Water productivity normalized for } \mathrm{ET}_{\mathrm{o}} \text { and } \mathrm{CO}_{2} \text { during yield } \\
\text { formation (as } \% \mathrm{WP}^{*} \text { before yield formation) }\end{array}$ & 100 \\
\hline \multicolumn{3}{|c|}{ 3.2 Harvest index } \\
\hline \multirow[t]{5}{*}{ Hlo } & Reference harvest index & 0.49 \\
\hline & Upper threshold for water stress during flowering on $\mathrm{HI}$ & 0.82 \\
\hline & $\begin{array}{l}\text { Possible increase (\%) of } \mathrm{HI} \text { due to water stress before } \\
\text { flowering }\end{array}$ & 12 (strong) \\
\hline & $\begin{array}{l}\text { Coefficient describing positive effect of restricted } \\
\text { vegetative growth during yield formation on } \mathrm{HI}\end{array}$ & Moderate \\
\hline & $\begin{array}{l}\text { Coefficient describing negative effect of stomatal closure } \\
\text { during yield formation on } \mathrm{HI}\end{array}$ & Moderate \\
\hline
\end{tabular}




\begin{tabular}{|c|c|c|}
\hline & Excess of potential fruits & Moderate \\
\hline & Allowable maximum increase (\%) of specified $\mathrm{HI}$ & 15 \\
\hline \multicolumn{3}{|c|}{ 4. Stresses } \\
\hline \multicolumn{3}{|c|}{ 4.1 Soil water stress } \\
\hline$P_{\text {exp,lower }}$ & $\begin{array}{l}\text { Lower threshold of water stress for triggering inhibited } \\
\text { canopy expansion }\end{array}$ & 0.60 \\
\hline \multirow[t]{2}{*}{$P_{\text {exp,upper }}$} & $\begin{array}{l}\text { Upper threshold for canopy expansion (canopy expansion } \\
\text { seizes) }\end{array}$ & 0.27 \\
\hline & $\begin{array}{l}\text { Shape factor for water stress coefficient for canopy } \\
\text { expansion }\end{array}$ & 3.5 \\
\hline \multirow[t]{2}{*}{$\mathrm{P}_{\text {sto }}$} & Upper threshold for stomata closure & 0.60 \\
\hline & $\begin{array}{l}\text { Shape factor for water stress coefficient for stomatal } \\
\text { control }\end{array}$ & 3.0 \\
\hline \multirow[t]{2}{*}{$P_{\text {sen }}$} & Upper threshold for early senescence due to water stress & 0.60 \\
\hline & $\begin{array}{l}\text { Shape factor for water stress coefficient for canopy } \\
\text { senescence }\end{array}$ & 3.5 \\
\hline \multirow[t]{2}{*}{$\mathrm{P}_{\mathrm{pol}}$} & $\begin{array}{l}\text { Upper threshold of soil water depletion for failure of } \\
\text { pollination }\end{array}$ & 0.80 \\
\hline & Vol.\% at anaerobiotic point (with reference to saturation) & 15 \\
\hline
\end{tabular}

b. Crop parameters for simulations in growing degree days

\begin{tabular}{|l|l|l|}
\hline Symbol & Description & Value \\
\hline \multicolumn{2}{|l|}{ Threshold air temperatures } & \\
\hline$T_{\text {base }}$ & Base temperature $\left({ }^{\circ} \mathrm{C}\right)$ & 0 \\
\hline$T_{\text {upper }}$ & Upper temperature $\left({ }^{\circ} \mathrm{C}\right)$ & 18 \\
\hline Development of green canopy cover & \\
\hline & Time from sowing to emergence (GDD) & 135 \\
\hline CGC & Canopy growth coefficient (fraction per GDD) & 0.813 \\
\hline & Time from sowing to start senescence (GDD) & 1315 \\
\hline CDC & Canopy decline coefficient (fraction per GDD) & 0.602 \\
\hline & Time from sowing to maturity & 1675 \\
\hline
\end{tabular}




\begin{tabular}{|l|l|l|}
\hline \multicolumn{2}{|l|}{ Flowering } & Time from sowing to flowering (GDD) \\
\hline & Length of flowering stage (GDD) & 950 \\
\hline Air temperature stress & 215 \\
\hline & $\begin{array}{l}\text { Minimum air temperature below which } \\
\left.\text { pollination starts to fail (cold stress, }{ }^{\circ} \mathrm{C}\right)\end{array}$ & 5 \\
\hline & $\begin{array}{l}\text { Maximum air temperature above which } \\
\left.\text { pollination starts to fail (heat stress, }{ }^{\circ} \mathrm{C}\right)\end{array}$ & 30 \\
\hline & $\begin{array}{l}\text { Minimum growing degrees required for full } \\
\text { biomass production }\left({ }^{\circ} \mathrm{C} \text { - day) }\right.\end{array}$ & 15 \\
\hline
\end{tabular}

